\title{
Impact of Major Crops on GDP (Pakistan Case)
}

\author{
Ashiq Hussain ${ }^{1}$, Muhammad Ajmair ${ }^{2}$ \\ ${ }^{1}$ Director, Mian Muhammad Nukhash Library, Mirpur AJK, Pakistan \\ ${ }^{2}$ Assistant Professor, Mirpur University of Science and Technology, AJK, Pakistan
}

\begin{abstract}
This paper is an attempt to investigate the relationship between GDP and Major crops(wheat, rice, maize, cotton and sugarcane) of Pakistan. Secondary data for 30 years from 1980 to 2010 was used for this purpose. The first step in the empirical analysis involves testing the time series characteristics of the data series using ADF tests. All the variables used in this study are stationary in their first differences. Simple Linear regression models are used to see the impacts of major crops on GDP of Pakistan. Regarding the hypotheses of the study, it is concluded that the entire hypothesis has a positive impact on GDP, partially accepted.
\end{abstract}

Keywords: GDP, Wheat, Rice, Cotton, Sugarcane

\section{Introduction}

Allah Almighty has blessed Pakistan with fertile lands where we are growing almost all types of crops. Wheat, Rice and Cotton are the export crops of Pakistan.

Today, Agriculture in Pakistan remains to be a large contributor to the country's economic mak e up but the manufacturing industry is slowly growing its share.(www.google.com/Agriculture in pakistan.com)

Agriculture in Pakistan now contributes 23\% to the national economy. As far as employment rate is concerned, $44 \%$ of the labor force in Pakistan works for the agriculture sector. Agriculture in Pakistan used to contribute $53 \%$ of the national economy but has now declined to $23 \%$ when the manufacturing industry is going up to as much as $55 \%$ of the GDP. Agriculture remains to be an important economic contributor as in fact Pakistan is the largest producers and suppliers of agricultural products according to the 2005 Food and Agriculture Organization.

Source :-(www.google.com/Agriculture in pakistan.com)

Nearly 62 percent of the country's population resides in rural areas, and is directly or indirectly linked with agriculture for their livelihood.

Pakistan's agricultur e has experienced rapid growth since the 1960s. The average annual growth of about $4 \%$ over the last four decades. Despite rising per capita income, food demand is likely to grow rapidly given the low level of current per capita income. Recent projections for future food supply and demand, call for sustained efforts for increasing production of essential items (wheat, edible oils, etc.).(www.google.com/Agriculture importance pdf)

Today, Agriculture in Pakistan remains to be a large contributor to the country's economic make up but the manufacturing industry is slowly growing its share. Other sectors like food processing, textile, chemical manufacturing and iron and steel now have strong contribution to the national economy in recent years.
Agriculture in Pakistan used to contribute 53\% of the national economy but has now declined to $23 \%$ when the manufacturing industry is going up to as much as $55 \%$ of the national pakistan.mht)

\subsection{Crop Situation}

There are two principal crop seasons in Pakistan, namely the "Kharif", the sowing season of which begins in April-June and harvesting during October-December; and the "Rabi", which begins in October-December and ends in April-May. Rice, sugarcane, cotton, maize, mong, mash, bajra and jowar are "Kharif" crops while wheat, gram, lentil (masoor), tobacco, rapeseed, barley and mustard are "Rabi" crops. Major crops, such as, wheat, rice, cotton and sugarcane account for 82.0 percent of the value added in the major crops. The value added in major crops accounts for 32.8 percent of the value added in overall agriculture. Thus, the four major crops (wheat, rice, cotton, and sugarcane), on average, contribute 33.1 percent to the value added in overall agriculture and 7.1 percent to GDP.(www.google.com/Agriculture crop situation pdf)

\subsection{Major Crops}

Important agricultural crops in Pakistan are the following:

- Wheat

- Sugarcane

- Cotton

- $\quad$ Rice

- Maize

(www.google.com/Agriculture in pakistan.com)

\section{Literature Review}

Ekpo and Egwaikhide (1994) observed that Nigeria agricultural export has enlarged to include cocoa beans and palm kernel. Statistics indicate that in 1960 agricultural export commodities contributed well over $75 \%$ of total annual merchandise exports. In $1940^{\circ e} \mathrm{~s}$ and $50^{\text {ec }} \mathrm{s}$ Nigeria was ranked very high in the production and exportation of major crops in the world. For instance, Nigeria was the largest exporter of palm oil and palm kernel, second to Ghana in cocoa and third position in the exportation of groundnut. 


\section{International Journal of Science and Research (IJSR) \\ ISSN (Online): 2319-7064 \\ Index Copernicus Value (2013): 6.14 | Impact Factor (2015): 6.391}

Dr. Hazoor Muhammad SabirandSafdarHussainTahir (2012) investigated the impact of different macroeconomic variables on the welfare of the poor in Pakistan, through annual time series data from 1981-2010. In this study, through annual time series data from 1981-2010, the multiple regression technique was applied to detect the relation between macroeconomic variables and poverty. Inflation, GDP growth, population growth, major crops, minor crops, livestock and per capita income were taken as independent variables while poverty (HCI) as dependent variable. The study results revealed that GDP growth rate per capita income, major crops, minor crops and livestock had negative impact while inflation and population growth rate had positive impact upon poverty. The conclusions drawn from the study are that in the long run, the reduction in poverty in Pakistan is to be driven by the changes in the macroeconomic variables.

R. J. Cody Markelz et al. (2011). Predict about future of ecosystem function and food supply from staple C4 crops, such as maize, depend on elucidation of the mechanisms by which environmental change and growing conditions interact to determine future plant performance. To test the interactive effects of elevated [CO2], drought, and nitrogen (N) supply on net photosynthetic CO2 uptake (A) in the world's most important C4 crop, maize (Zea mays) was grown at ambient [CO2] (;385 ppm) and elevated [CO2] (550 ppm) with either high $\mathrm{N}$ supply (168 kg $\mathrm{N}$ ha21 fertilizer) or limiting $\mathrm{N}$ (no fertilizer) at a site in the US Corn Belt. A mid-season drought was not sufficiently severe to reduce yields, but caused significant physiological stress, with reductions in stomatal conductance (up to 57\%), A (up to $44 \%$ ), and the in vivo capacity of phosphoenolpyruvate carboxylase (up to 58\%). There was no stimulation of A by elevated [CO2] when water availability was high, irrespective of $\mathrm{N}$ availability. Elevated [CO2] delayed and relieved both stomatal and nonstomatal limitations to $\mathrm{A}$ during the drought. Limiting $\mathrm{N}$ supply exacerbated stomatal and non-stomatal limitation to A during drought. However, the effects of limiting $\mathrm{N}$ and elevated [CO2] were additive, so amelioration of stress by elevated [CO2] did not differ in magnitude between high $\mathrm{N}$ and limiting $\mathrm{N}$ supply. These findings provide new understanding of the limitations to C4 photosynthesis that will occur under future field conditions of the primary region of maize production in the world.

Leakey, (2009) Using FACE technology to test the effect of elevated [CO2] on maize grown without fertilizer inputs resulted in an experiment with greater relevance to the limiting $\mathrm{N}$ supply under which $\mathrm{C} 4$ crops are grown in many other regions of the world .

Strasberg, (1997) reported that In the Zambezi Valley of Mozambique, government has granted the cotton and tobacco companies monopsony rights, i.e., farmers are not permitted to sell outside the contracting scheme they are assigned to. These schemes are normally implemented on land for which individual farmers or farming communities have use rights, but there are cases in other parts of the country where the firms use designated areas or blocks within their own land concessions for that purpose.
Walker et al., 2004; Benficaet al., (2005) indicate that growers of cash crops, particularly cotton and tobacco, tend to have crop and total incomes somewhat higher than those of non-growers. 4 those studies have also indicated that a number of farmers engaged in the contracting schemes have losses in their operations. On the other hand, the extent of indirect effects through labor markets and other linkages, which can potentially foster broader income distribution and impact poverty reduction across different household groups, have not been fully documented.

Benfica, et al., (2005) reported that finally, technological and environmental spillovers in tobacco growing areas need to be more closely examined. On the positive side, growers and non-growers both are farmer likely to apply fertilizer on food crops than are farmers in other areas of the country; it is likely that the provision of fertilizer for tobacco has contributed to this pattern, through a combination of some diversion to food crops32 and greater familiarity with the input leading to greater use. On the negative side, the rate of tree cutting by tobacco growers far surpasses the rate of planting.

Strasberg, (1997) reviewed that Most schemes take the form of forward resource/management contracts. 3 the standard contract consists in the firms supplying seeds, other inputs (including chemicals), and technical assistance to farmers on credit for use on specific crops. Farmers agree to utilize the inputs as instructed, and to sell all their production to the firms at harvest at agreed-upon prices. The costs initially supported by the firms, together with any interest charge, are deducted at the time of the harvest. In the Zambezi Valley of Mozambique, government has granted the cotton and

Akintayo(2011) reported that as with most other crops in Nigeria, rice yields are low, averaging about 1.8 tons of paddy per hectare, compared to national potential average of 3 tons per hectare for upland system and 5 tons per hectare for the lowland system (Akintayo 2011). In general, food crop production in Nigeria is far below potential and demand is greater than locally produced supply.

Musa (2010) studies on credit access in rural Nigeria are mostly focused on the relationship between credit access and some indicator of agricultural output such as profitability, productivity, or production. In Zamfara State, formal loan beneficiaries, mostly from the Zamfara Comprehensive Agricultural Revolution Program and commercial banks, recorded higher yields in the major crops and also recorded higher net farm incomes.

\section{Methodology}

This section discusses the methodologies that are employed to meet the objectives of the study. The variables used in this study " impact of major crops on GDP" include growth of gross domestic product (gGDP); dependent variable, and growth of wheat (gWHT), growth of Rice (gRIC), growth of Maize (gMAZ), growth of Cotton (gCTN), growth of Sugarcane (gSCN) as independent variables.

The sample period covers time series data from 1981 to 2010. All the relevant data is obtained from Economic 


\section{International Journal of Science and Research (IJSR) \\ ISSN (Online): 2319-7064 \\ Index Copernicus Value (2013): 6.14 | Impact Factor (2015): 6.391}

Survey of Pakistan, Many economic time series are nonstationary at level. One way of getting the interesting information about the stationary of time series is to plot the original series and making correlation at both level and first difference. The second, most rigorous way is to use the Augmented Dickey Fuller (ADF) which is the wider version of the standard Dickey Fuller (DF). This test is employed to verify the presence of unit root in the series. ). (MOHAMMAD AMZAD HOSSAIN)

\subsection{Implication of Staionary and Non-Stationarty Time Series}

As we begin to develop models for time series, we want to know whether the underlying stochastic process that generated the series can be assumed to be invariant with respect to time. If the characteristics of stochastic process change over time, i.e., if the process is non-stationary, it will often be difficult to represent the time series over past and future intervals of time by a simple algebraic model--the random walk with drift is an example of non-stationary process for which a simple forecasting model can be constructed. By contrast, if the stochastic process is fixed in time, i.e., if it is stationary then one can model the process via an equation with fixed coefficients that can be estimated from past data. (Joon Y. Park, 2005). Observing the results of Unit-Root Test in the result section; it is clear that all the data series are stationary at same order of integration I(1).

\subsection{Mathematical Presentation of Model}

To test the relationship between gross domestic product and different major crops following model is used:

gGDP $=f$ (gWht, gRic, gMaz, gCtn, gScn, $\varepsilon$ )

where

gGDP: Growth of Gross Domestic Product

gWht: Growth of wheat.

gRic: Growth of Rice

gMaz: Growth of Maize.

gCtn : Growth of Cotton.

gScn: Growth of sugarcane.

ع: Error Term

\subsection{Model Specifications}

gGDP $=\mathbf{\beta 0}+\mathbf{\beta 1}($ gWht $)+\mathbf{\beta 2}($ gRic) $+\mathbf{\beta 3}($ gMaz) $+\mathbf{\beta 4}$ $(\mathrm{gCtn})+ß 5(\mathrm{gScn})+\varepsilon$

\section{Results and Discussion}

\subsection{Analysis of Results of Unit Roots (Table 4.1)}

To test the stationary we have used ADF test because DF test is based only on AR (1) process while ADF test extra lagged terms of dependent variable in order to eliminate auto-correlation. In table (4.1) I tested the null hypothesis of unit root against alternative of stationary at level or first difference.

The augmented Dickey-Fuller (ADF) statistic, used in the test, is a negative number. The more negative it is, the stronger the rejection of the hypothesis, that there is unit root, at some level of confidence. In one example, with three lags, a value of -3.23 constituted rejections at the $\mathrm{p}$-value of 10 percent.

Table 4.1: ADF Test Results of five major crops and GDP

\begin{tabular}{|c|c|c|c|c|}
\hline \multirow{2}{*}{ Variables } & \multicolumn{2}{|c|}{ Level } & \multicolumn{2}{c|}{ First Difference } \\
\cline { 2 - 5 } & $\begin{array}{c}\text { Intercept } \\
\text { and Trend }\end{array}$ & $\begin{array}{c}\text { Order } \\
\text { of } \\
\text { Integration }\end{array}$ & $\begin{array}{c}\text { Intercept } \\
\text { and Trend }\end{array}$ & $\begin{array}{c}\text { Order } \\
\text { of } \\
\text { Integration }\end{array}$ \\
\hline gwht $_{\mathbf{t}}$ & $\begin{array}{c}-3.64^{* *} \\
(-3.59)\end{array}$ & $\mathrm{I}(1)$ & $\begin{array}{c}-8.99^{*} \\
(-4.35)\end{array}$ & $\mathrm{I}(0)$ \\
\hline gric $_{\mathbf{t}}$ & $\begin{array}{c}-3.64^{* *} \\
(-3.58)\end{array}$ & $\mathrm{I}(1)$ & $\begin{array}{c}-6.96^{*} \\
(-4.35)\end{array}$ & $\mathrm{I}(0)$ \\
\hline gmaz $_{\mathbf{t}}$ & $-3.81^{* *}$ & $\mathrm{I}(1)$ & $-3.64^{* *}$ & $\mathrm{I}(0)$ \\
& $(-3.59)$ & & $(-3.59)$ & \\
\hline $\mathbf{g c t n}_{\mathbf{t}}$ & $-4.58^{*}$ & $\mathrm{I}(1)$ & $-6.32^{*}$ & $\mathrm{I}(0)$ \\
& $(-4.35)$ & & $(-4.35)$ & \\
\hline $\mathbf{g s c n}_{\mathbf{t}}$ & $-5.89^{*}$ & $\mathrm{I}(1)$ & $-3.98^{* *}$ & $\mathrm{I}(0)$ \\
& $(-4.35)$ & & $(-3.59)$ & \\
\hline $\mathbf{g g d p}_{\mathbf{t}}$ & $-3.27^{* * *}$ & $\mathrm{I}(1)$ & $-4.32^{* *}$ & $\mathrm{I}(0)$ \\
& $(-3.23)$ & & $(-3.59)$ & \\
\hline
\end{tabular}

Note: *denotes the rejection of the null hypothesis at 1 percent level of significance,

**denotes the rejection of the null hypothesis at 5 percent level of significance and

***at 10 percent level of significance. Values in the parenthesis are MacKinnon critical values for rejection of hypothesis of a unit root. Legend: gWht is growth of wheat, gRic is growth of rice,

gMaz is growth of maize,

gCtn is growth of cotton and

gScn is growth of sugarcane.

\subsection{Simple Linear Regression}

In statistics, simple linear regression is the least squares estimator of a linear regression model with a single explanatory variable. In other words, simple linear regression fits a straight line through the set of $n$ points in such a way that makes the sum of squared residuals of the model (that is, vertical distances between the points of the data set and the fitted line) as small as possible.

Linear regression is an approach to modeling the relationship between a scalar dependent variable and one or more explanatory variables denoted by $\mathrm{X}$. The case of one explanatory variable is called simple linear regression

In linear regression, data is modeled using linear predictor functions, and unknown model parameters are estimated from the data. Such models are called linear models. Most commonly, linear regression refers to a model in which the conditional mean of $\mathrm{y}$ given the value of $\mathrm{X}$ is an affine function of $X$. Less commonly, linear regression could refer to a model in which the median, or some other quintile of the conditional distribution of $\mathrm{y}$ given $\mathrm{X}$ is expressed as a linear function of $\mathrm{X}$. Like all forms of regression analysis, linear regression focuses on the conditional probability distribution of $\mathrm{y}$ given $\mathrm{X}$, rather than on the joint probability distribution of $\mathrm{Y}$ and $\mathrm{X}$, which is the domain of multivariate analysis.Source:http://en.wikipedia.org/wiki/Linear_regressi on 


\section{International Journal of Science and Research (IJSR) \\ ISSN (Online): 2319-7064}

Index Copernicus Value (2013): 6.14 | Impact Factor (2015): 6.391

\begin{tabular}{|l|l|l|l|l|l|}
\hline & gCTN & gMAZ & gRIC & gSCN & gWHT \\
\hline Constant & 14.84 & 15.05 & 14.64 & 15.28 & 14.62 \\
& $(16.71)$ & $(15.13)$ & $(16.85)$ & $(17.18)$ & $(16.32)$ \\
\hline gGDP & 0.04 & 0.01 & 0.15 & -0.07 & 0.16 \\
& $(1.20)$ & $(0.12)$ & $(1.87)$ & $(-0.93)$ & $(1.62)$ \\
\hline $\mathrm{R}^{2}$ & 0.05 & 0.00 & 0.11 & 0.03 & 0.09 \\
\hline
\end{tabular}

\subsection{Regression Results}

These results are taken from e-views. Here the dependent variable is gGDP and independent variable is gCTN, gMAZ, gRIC, gSCN and gWHT. The results of simple linear regression model describe that the revenues from gCTN have no significant impact on gGDP . R-square is also very low by $4 \%$, its mean no significant role of gCTN on gGDP .gMAZ have no significant impact on gGDP. Rsquare is also very low by $0 \%$, it means no role of gMAZ on gGDP of Pakistan.gRIC have positive impact on gGDP.Rsquare is also not very low by $11 \%$. It means there is positive and little role of gRIC on gGDP of Pakistan. gSCN has negative impact on gGDP. R-square is also very low by $3 \%$. It means there is negative role of gSCN on gGDP of Pakistan. gWHT has positive impact on gGDP. R-square is also not very low by $9 \%$. It means there is little role of gWHT on gGDP of Pakistan.

\section{Conclusion}

This paper is an attempt to investigate the relationship between GDP and wheat, rice, maize, cotton and sugarcane sector of the economy of Pakistan. Secondary data for 30 years from 1980 to 2010 was used for this purpose. The first step in the empirical analysis involves testing the time series characteristics of the data series using ADF tests. All the variables used in this study are stationary in their first differences. Simple Linear regression models are used to see the impacts of major crops on GDP of Pakistan.

Regarding the hypotheses of the study it is concluded that the entire hypothesis has a positive impact on GDP partially accepted. Because all the independent variables show a positive relationship with GDP growth except sugarcane that not only shows the negative relationship but also gives a significant result.

\section{References}

[1] www.google.com/history of Pakistan

[2] www.google.com/introduction of Pakistan

[3] www.google.com/major crops of Pakistan

[4] Ekpo, A \&Egwaikhide, F 1994, Exports and Economic growth in Nigeria: A Reconsideration of the evidence: Journal of Economic Management, 1 (1): 100-115

[5] Dr. Hazoor Muhammad Sabirand SafdarHussainTahir (2012). The Impact Of Different Macroeconomic Variables On Poverty In Pakistan. Interdisciplinary Journal Of Contemporary Research In Business .Vol 3, No 10

[6] R. J. Cody Markelz, Reid S. Strellner and Andrew D. B. Leakey (2011). Impairment of C4 photosynthesis by drought is exacerbatedby limiting nitrogen and ameliorated by elevated [CO2] in maize. Journal of Experimental Botany, Vol. 62, No. 9, pp. 3235-3246, 